\title{
PENGARUH ETIKA, PENDIDIKAN, DAN PENGALAMAN TERHADAP KUALITAS AUDIT DENGAN PROFESIONALISME SEBAGAI VARIABEL INTERVENING (STUDI PADA INSPEKTORAT KABUPATEN BANYUWANGI)
}

\author{
Nurul Alfiyah ${ }^{1}$ \\ Email:nu2fia@yahoo.co.id \\ Siti Maria Wardayati ${ }^{2}$ \\ Email: siti.maria@unej.ac.id \\ Agung Budi Sulistiyo3 \\ Email:agungbudi.feb@unej.ac.id
}

\begin{abstract}
This study aims to examine and analyze the influence of ethics, education, and experience to professionalism and to test and analyze the effect of ethics, education, experience, and professionalism of the quality audit at the office of the Inspectorate of Banyuwangi. Where the sampling technique using census method with auditors who have the certification criteria of functional positions auditor (JFA) and follow continuous professional education and training (continuing professional education) totaling 28 people. The results showed that ethics significant effect on audit quality. Then the second hypothesis education variable has no effect on audit quality, this indicates the second hypothesis is rejected. The third hypothesis is that experience does not significantly affect professionalism. Fourth hypothesis ethics significantly affect audit quality. Education not significant effect on audit quality, this indicates a fifth hypothesis is rejected. The sixth hypothesis experience significant effect on audit quality. And the results of the seventh hypothesis professionalism significant effect on audit quality.
\end{abstract}

Keywords: ethics, education, experience, professionalism and quality of the audit.

\section{PENDAHULUAN}

Dewasa ini masyarakat menuntut agar lembaga sektor publik semakin meningkatkan kualitas dalam pelayanan, mutu serta pengelolaan organisasi. Audit pemerintah merupakan kewajiban utama pemerintah sebagai bentuk pertanggung

1 Corresponding Author: Alumni Jurusan Akuntansi Fakultas Ekonomi Universitas Jember,

Jl. Kalimantan 37, 68121, Jember, Indonesia

2,3 Jurusan Akuntansi Fakultas Ekonomi Universitas Jember, Jl. Kalimantan 37, 68121, Jember,

Indonesia 
jawaban kepada rakyat. Organisasi sektor publik pemerintah adalah lembaga yang menjalankan roda pemerintahan yang sumber legitimasinya berasal dari rakyat. Salah satu unit yang melakukan audit/pemeriksaan terhadap pemerintah daerah adalah inspektorat daerah. Peran dan fungsi inspektorat provinsi, kabupaten/kota secara umum diatur dalam pasal 4 Peraturan Menteri Dalam Negeri No 64 Tahun 2007. Pasal 4 menyatakan bahwa dalam melaksanakan tugas pengawasan urusan pemerintahan, inspektorat provinsi, kabupaten/kota mempunyai fungsi sebagai berikut: pertama, perencanaan program pengawasan; kedua, perumusan kebijakan dan fasilitas pengawasan; dan ketiga, pemeriksaan, pengusutan, pengujian, dan penilaian tugas pengawasan. Peraturan Menteri Negara Pendayagunaan Aparatur Negara nomor: PER/05/M.PAN/03/2008 tentang pengukuran kualitas audit atas laporan keuangan khususnya yang dilakukan oleh Aparatur Pengawasan Internal Pemerintah (APIP) wajib menggunakan Standar Pemeriksaan Keuangan Negara (SPKN) yang tertuang dalam Peraturan Badan Pemeriksa Keuangan Republik Indonesia Nomor 01 Tahun 2007.

Penelitian ini berfokus pada empat aspek yaitu etika, pendidikan, pengalaman, dan profesionalisme yang diduga berpengaruh terhadap kualitas audit pada kantor inspektorat kabupaten Banyuwangi. Penelitian ini merupakan studi lanjutan dari penelitian yang dilakukan oleh Cahayu (2013) dan Wardayati et.al (2015). Beberapa penelitian terhadap variabel etika yaitu Kisnawati (2012), Kovinna et al. (2014) dan Ashari (2011). Untuk variabel pendidikan penelitian juga pernah dilakukan oleh Pebryanto (2013), Subhan (2012). Sedangkan untuk variabel pengalaman penelitian sebelumnya pernah dilakukan oleh Sylvie Bolang et al. (2013), Budi et al. (2004) dan Atmawinata (2014).

Tabel 1 Daftar Opini LKPD Tahun 2010 - 2014 Kabupaten Banyuwangi dan sekitarnya

\begin{tabular}{llllll}
\hline $\begin{array}{c}\text { Entitas Pemerintah } \\
\text { Daerah }\end{array}$ & Tahun 2010 & Tahun 2011 & Tahun 2012 & Tahun 2013 & Tahun 2014 \\
\hline Kab.Banyuwangi & WDP & WDP & WTP & WTP & WTP DPP \\
\hline Kab.Bondowoso & WDP & WTP DPP & WTP & WDP & WTP DPP \\
\hline Kab.Jember & WDP & WDP & WTP & WDP & WDP \\
\hline Kab.Situbondo & WDP & WDP & WDP & WDP & WTP DPP \\
\hline Kab.Probolinggo & WDP & WDP & WDP & WTPDPP & WTP DPP \\
\hline Sumber : Ikhtisar Hasil Pemeriksaan BPK Semester 1 Tahun 2015 & &
\end{tabular}

Dari tabel tersebut dapat kita lihat bahwa pada tahun 2014 Kabupaten Banyuwangi mengalami penurunan kualitas opini dari WTP menjadi WTP DPP. Hal ini diduga karena Kabupaten Banyuwangi masih dalam tahap awal dalam penerapan Standar Akuntansi Pemerintahan (SAP) berbasis akrual sesuai dengan Peraturan Pemerintah No.71 tahun 2010. tentang Standar Akuntansi Pemerintahan (SAP) berbasis akrual sebagai pengganti dari PP No.24 tahun 2005 yang menetapkan bahwa seluruh Pemerintah Daerah wajib menerapkan SAP berbasis akrual paling lambat tahun Anggaran 2015. Dan Kabupaten Banyuwangi merupakan satu - satunya Kabupaten di Jawa Timur yang pada tahun 2014 sudah menerapkan Akrual Basis sehingga Kabupaten Banyuwangi menjadi rujukan dari Kabupaten - Kabupaten lainnya. 


\section{LANDASAN TEORI DAN PERUMUSAN HIPOTESIS}

\subsection{Teori Keagenan (Agency Theory)}

Teori ini mengasumsikan bahwa masing-masing individu semata-mata termotivasi oleh kepentingan dirinya sendiri sehingga menimbulkan konflik kepentingan antara prinsipal dan agen. Prinsipal mengontrak agen untuk melakukan pengelolaan sumber daya dalam perusahaan dan berkewajiban untuk memberikan imbalan kepada agen sedangkan agen berkewajiban melakukan pengelolaan sumber daya yang dimiliki oleh perusahaan dan bertanggungjawab atas tugas yang dibebankan kepadanya (Jensen dan Meckling 1976). Mardiasmo (2007, 20-21) menjelaskan bahwa pengertian akuntabilitas publik sebagai kewajiban pihak pemegang amanah (agent) untuk memberikan pertanggungjawaban, menyajikan, melaporkan, dan mengungkapkan segala aktivitas dan kegiatan yang menjadi tanggung jawabnya kepada pihak pemberi amanah (principal) yang memiliki hak untuk meminta pertanggungjawaban tersebut.

Keagenan dalam pengelolaan keuangan daerah diinterpretasikan dalam dua hubungan yaitu: (1) hubungan yang terjadi rakyat sebagai prinsipal dan kepala daerah sebagai agen; dan (2) hubungan kepala daerah sebagai prinsipal dan kepala SKPD sebagai agen. Undang-Undang Nomor 12 tahun 2008 tentang Pemerintahan Daerah, menyatakan kepala daerah dipilih oleh rakyat. Mekanisme pemilihan ini merupakan pemberian otoritas eksekutif dan pelimpahan wewenang rakyat kepada pemerintah daerah (gubernur, bupati/walikota). Hubungan kepala daerah sebagai prinsipal dan kepala SKPD sebagai agen tercermin dalam Permendagri Nomor 59 tahun 2007 tentang Pedoman Pengelolaan Keuangan Daerah yang menyatakan bahwa kekuasaan pengelolaan keuangan daerah dilaksanakan oleh kepala Satuan Kerja Pengelola Keuangan Daerah (SKPKD) selaku Pejabat Pengelola Keuangan Daerah (PPKD) dan kepala Satuan Kerja Perangkat Daerah (SKPD) selaku pejabat pengguna anggaran (PA) atau pengguna barang daerah. Kedudukan kepala SKPD dan PPKD adalah menerima wewenang dari kepala daerah selaku pemegang kekuasaan pengelolaan keuangan daerah.

\subsection{Teori Kompetensi}

Teori kompetensi sumber daya manusia yang dikemukakan oleh Beer dan Spector (1985) dikenal dengan teori "aset". Teori ini menjelaskan bahwa setiap karyawan dinilai memiliki aset bagi suatu organisasi, yang saling mempengaruhi untuk menghasilkan kompetensi. Menurut Wibowo (2008, 86), kompetensi sebagai karakteristik dari seseorang yang dapat diperlihatkan, yang meliputi pengetahuan, ketrampilan, teori jendela yang dikemukakan Donald (dalam Kamidin 2010) di sebut dengan teori KSEA (Knowledge, Skill, Expert, dan Attitude). Fokus atau inti teori jendela ini disebut adalah kompetensi sumber daya manusia. Setiap individu sumber daya manusia yang memiliki pengetahuan ditunjang dengan keterampilan merupakan sumber daya manusia yang handal. Sumber daya manusia yang memiliki keterampilan ditunjang dengan keahlian pada bidang tugas yang ditekuni sebagai sumber daya manusia yang kapabilitas. Sumber daya manusia yang memiliki keahlian dituntut untuk mampu bersikap profesional, akan menjadi sumber daya manusia yang memiliki kompetensi yang handal dan mandiri. 


\subsection{Standar Kompetensi Auditor}

Pengertian Audit menurut peraturan menteri pendayagunaan aparatur negara nomor PER/05/M.PAN/03/2008, audit adalah proses identifikasi masalah, analisis, dan evaluasi bukti yang dilakukan secara independen, obyektif, dan profesional berdasarkan standar audit, untuk menilai kebenaran, kecermatan, kredibilitas, efektivitas, efisiensi, dan keandalan informasi pelaksanaan tugas dan fungsi instansi pemerintah.

Standar Kompetensi Auditor dalam Peraturan Kepala Badan Pengawasan Keuangan Dan Pembangunan Nomor : PER - 211/K/JF/2010 Tentang Standar Kompetensi Auditor dijelaskan bahwa kompetensi adalah kemampuan dan karakteristik yang dimiliki seorang Pegawai Negeri Sipil berupa pengetahuan, keahlian, dan sikap perilaku yang diperlukan dalam pelaksanaan tugas jabatannya. Sedangkan standar kompetensi auditor adalah ukuran kemampuan minimal yang harus dimiliki auditor yang mencangkup aspek pengetahuan (knowledge), ketrampilan/keahlian (skill), dan sikap perilaku (attitude) untuk dapat melakukan tugas - tugas dalam jabatan fungsional auditor dengan hasil baik.

\subsection{Proses Audit Sektor Publik}

Langkah - langkah dalam proses audit yang dijelaskan oleh Bastian $(2007,28)$ adalah perencanaan (planning), pelaksanaan (executing), dan pelaporan (reporting). Isi dokumentasi dari kertas kerja memperlihatkan pemeriksaan telah direncanakan dan disupervisi dengan baik, pemahaman yang memadai atas struktur pengendalian internal yang telah diperoleh untuk merencanakan audit dan menentukan sifat, saat dan lingkup pengujian yang telah dilakukan, bukti audit yang telah diperoleh, prosedur yang telah diterapkan, dan pengujian yang telah dilaksanakan sebagai dasar yang memadai untuk menyatakan pendapat atas laporan keuangan yang diaudit.

\subsection{Pengawasan Keuangan Daerah}

Menurut Peraturan Pemerintah Republik Indonesia Nomor 79 tahun 2005 tentang Pedoman Pembinaan dan Pengawasan Penyelenggaraan Pemerintah Daerah menyatakan bahwa pengawasan atas penyelenggaraan pemerintah daerah adalah proses kegiatan yang ditujukan untuk menjamin agar pemerintah daerah berjalan secara efisien dan efektif sesuai dengan rencana dan ketentuan peraturan perundangundangan. Pengawasan pelaksanaan urusan pemerintahan di daerah meliputi pelaksanaan urusan pemerintah di daerah kabupaten/kota terdiri dari: (1) pelaksanaan urusan pemerintah di daerah yang bersifat wajib; (2) pelaksanaan urusan pemerintah di daerah yang bersifat pilihan; dan (3) pelaksanaan urusan pemerintah menurut tugas pembantu. Pengawasan terhadap urusan pemerintah di daerah dilaksanakan oleh aparat pengawasan intern pemerintah sesuai dengan fungsi dan kewenangannya. Aparat pengawas intern pemerintah adalah inspektorat jenderal departemen, unit pengawasan lembaga pemerintah non-departemen, inspektorat provinsi, dan inspektorat kabupaten/kota. Inspektorat kabupaten/kota melakukan pengawasan terhadap: pelaksanaan urusan pemerintah di daerah kabupaten/kota, pelaksanaan pembinaan atas penyelenggaraan pemerintah desa, dan pelaksanaan urusan pemerintah desa. 


\subsection{Kualitas Audit}

Peraturan Menteri Negara Pendayagunaan Aparatur Negara nomor PER/05/M.PAN/03/2008 tentang Pengukuran Kualitas Audit Atas Laporan Keuangan, khususnya yang dilakukan oleh APIP, wajib menggunakan Standar Pemeriksaan Keuangan Negara (SPKN). Dalam lampiran 3 SPKN disebutkan bahwa: "Besarnya manfaat yang diperoleh dari pekerjaan pemeriksaan tidak terletak pada temuan pemeriksaan yang dilaporkan atau rekomendasi yang dibuat, tetapi terletak pada efektivitas penyelesaian yang ditempuh oleh entitas yang diperiksa. Manajemen entitas yang diperiksa bertanggung jawab untuk menindaklanjuti rekomendasi serta menciptakan dan memelihara suatu proses dan sistem informasi untuk memantau status tindak lanjut atas rekomendasi pemeriksa dimaksud. Jika manajemen tidak memiliki cara semacam itu, pemeriksa wajib merekomendasikan agar manajemen memantau status tindak lanjut atas rekomendasi pemeriksa. Perhatian secara terusmenerus terhadap temuan pemeriksaan yang material beserta rekomendasinya dapat membantu pemeriksa untuk menjamin terwujudnya manfaat pemeriksaan yang dilakukan" (paragraf 17). Kualitas auditor menurut Peraturan Menteri Negara Pendayagunaan Aparatur Negara No. Per/05/M.Pan/03/2008 tanggal 31 Maret 2008 adalah auditor yang melaksanakan tupoksi dengan efektif, dengan cara mempersiapkan kertas kerja pemeriksaan, melaksanakan perencanaan, koordinasi, dan penilaian efektivitas tindak lanjut audit, serta konsistensi laporan audit.

\subsection{Etika}

Peraturan Menteri Negara Pendayagunaan Aparatur Negara Nomor PER/05/M.PAN/03/2008 tentang Standar Audit Aparat Pengawasan Intern Pemerintah (APIP) menjelaskan kode etik adalah pernyataan tentang prinsip moral dan nilai yang digunakan oleh auditor sebagai pedoman tingkah laku dalam melaksanakan tugas pengawasan. Dasar yang melandasi penyusunan kode etik setiap profesi adalah kepercayaan masyarakat terhadap mutu jasa yang diberikan oleh profesi. Setiap profesi termasuk auditor yang menjual jasanya kepada masyarakat memerlukan kepercayaan dari masyarakat yang dilayaninya. Oleh karena itu, profesi tersebut perlu mengatur dan menetapkan ukuran mutu yang harus dicapai oleh auditornya. Aturan yang ditetapkan menyangkut aturan perilaku, yang mengatur perilaku auditor sesuai dengan tuntutan profesi, yang disebut dengan kode etik (Pusdiklatwas BPKP 2008). Kode etik menurut Standar Audit Aparat Pengawasan Intern Pemerintah (APIP) sebagai berikut: integritas, objektivitas, kerahasiaan, dan kompetensi.

\subsection{Pendidikan}

Dalam Peraturan Menteri Negara Pendayagunaan Aparatur Negara Nomor PER/05/M.PAN/03/2008 tentang Standar Audit APIP, latar belakang pendidikan pemeriksa adalah auditor Aparat Pemeriksa Intern Pemerintah (APIP) minimal Strata satu (S-1) atau yang setara, Agar tercipta kinerja audit yang baik maka APIP harus mempunyai kriteria tertentu dari auditor yang diperlukan untuk merencanakan audit, mengidentifikasi kebutuhan profesional auditor dan untuk mengembangkan teknik dan metodologi audit agar sesuai dengan situasi dan kondisi yang dihadapi unit yang dilayani oleh APIP. Untuk itu APIP juga harus mengidentifikasi keahlian yang belum tersedia dan mengusulkannya sebagai bagian dari proses rekrutmen. Aturan tentang tingkatan pendidikan formal minimal dan pelatihan yang diperlukan harus dievaluasi 
secara periodik guna menyesuaikan dengan situasi dan kondisi yang dihadapi unit yang dilayani oleh APIP.

\subsection{Pengalaman}

Sesuai dengan standar umum dalam Standar Profesional Akuntan Publik bahwa auditor disyaratkan memiliki pengalaman kerja yang cukup dalam profesi yang ditekuninya, serta dituntut untuk memenuhi kualifikasi teknis dan berpengalaman dalam industri-industri yang mereka audit (Arens et al. 2010). Pengalaman juga memberikan dampak pada setiap keputusan yang diambil dalam pelaksanaan audit sehingga diharapkan setiap keputusan yang diambil merupakan keputusan yang tepat. Hal tersebut mengindikasikan bahwa semakin lama masa kerja yang dimiliki auditor maka auditor akan semakin baik pula kualitas audit yang dihasilkan. Widiyanto dan Indrawati (2005) menerangkan bahwa pengalaman adalah keseluruhan pelajaran yang dipetik oleh seseorang dari peristiwa-peristiwa yang dialami dalam perjalanan hidupnya. Pengalaman kerja erat kaitannya dengan lama masa kerja dan banyaknya pemeriksaan yang dilakukan auditor. Semakin lama masa kerja sebagai auditor maka akan mempengaruhi dalam profesionalitasnya.

\subsection{Profesionalisme}

Profesionalisme auditor internal merupakan sikap, kemampuan, maupun kredibilitas dalam menjalankan profesi sebagai auditor internal. Profesionalisme juga terkait suatu usaha untuk mempertahankan kualitas suatu hasil pekerjaan atau meningkatkannya. Auditor harus menggunakan sikap profesionalismenya sejak dari tahap perencanaan audit untuk melaksanakan prosedur audit selama pekerjaan lapangan hingga penerbitan laporan audit (Rosina 2012). Menurut Irwansyah (2010) dalam Rosnidah $(2011,458)$, profesionalisme dapat dicerminkan ke dalam lima hal, yaitu pengabdian pada profesi, kewajiban sosial, kemandirian, keyakinan terhadap profesi, dan hubungan dengan sesama profesi.

\subsection{Hipotesis}

Penelitian ini memiliki 7 hipotesis. hipotesis pertama menyatakan etika berpengaruh terhadap profesionalisme. Hipotesis kedua menyatakan pendidikan berpengaruh terhadap profesionalisme. Hipotesis ketiga menyatakan pengalaman berpengaruh terhadap profesionalisme. Hipotesis keempat menyatakan etika berpengaruh terhadap kualitas audit. Hipotesis kelima menyatakan pendidikan berpengaruh terhadap kualitas audit. Hipotesis keenam menyatakan pengalaman berpengaruh terhadap kualitas audit. Dan hipotesis ketujuh menyatakan profesionalisme berpengaruh terhadap kualitas audit.

\section{METODE PENELITIAN}

Penelitian ini merupakan penelitian penjelasan (explanatory/confirmatory research. Dilihat dari jenis data yang dikumpulkan, maka penelitian ini termasuk penelitian dengan menggunakan data kuantitatif. Populasi dalam penelitian ini adalah seluruh pemeriksa yang bekerja di Inspektorat Kabupaten Banyuwangi yang ikut dalam tugas pelaksanaan yaitu sebanyak 28 orang. Teknik pengambilan sampel dalam penelitian ini menggunakan metode sensus yaitu penyebaran kuesioner dilakukan pada semua populasi. Responden yang menjadi responden tersebut adalah pemeriksa yang bekerja di Inspektorat Kabupaten Banyuwangi yang telah bersertifikasi. Bersertifikasi 
yang dimaksud di sini adalah auditor yang mempunyai sertifikasi Jabatan Fungsional Auditor (JFA) dan mengikuti pendidikan dan pelatihan profesional berkelanjutan (continuing profesional education). Adapun pemeriksa yang memenuhi kriteria tersebut adalah sebanyak 28 orang, sehingga sampel dalam penelitian ini adalah 28 orang. Data yang digunakan dalam penelitian ini adalah data primer yang diperoleh dari kuesioner.

Variabel eksogen adalah variabel yang mempengaruhi atau yang menjadi sebab perubahan timbulnya variabel endogen (Sugiyono 2009, 39). Variabel eksogen dalam penelitian ini adalah etika, pendidikan, dan pengalaman. Variabel intervening adalah variabel yang secara teoritis mempengaruhi hubungan antara variabel eksogen dengan variabel endogen menjadi hubungan tidak langsung, tidak dapat diamati atau diukur. Trucman (1998) (dalam Sugiyono 2009, 41). Variabel intervening dalam penelitian ini adalah profesionalisme. Variabel endogen adalah variabel yang dijelaskan atau dipengaruhi oleh variabel eksogen. Variabel endogen dalam penelitian ini adalah kualitas audit.

\section{METODE ANALISIS DATA}

\subsection{Statistika Deskriptif}

Analisis statistik deskriptif adalah analisis paling mendasar untuk menggambarkan keadaan data secara umum serta untuk analis data dengan tujuan pemahaman karakteristik sampel. Analisis statistik deskriptif terdiri atas statistik deskriptif responden dan statistik deskriptif variabel penelitian. Statistik deskriptif responden bertujuan untuk menyajikan informasi demografi responden, yang terdiri atas jenis kelamin, umur, jabatan/strata, dan pendidikan terakhir. Statistik deskriptif variabel penelitian bertujuan untuk menyajikan informasi mengenai nilai minimum, maksimum, mean dan standar deviasi dari variabel eksogen dan endogen (Indriantoro dan Supomo 2009, 170).

\subsection{Analisis Partial Least Square (PLS)}

Dalam penelitian ini, untuk menguji hipotesis, penelitian menggunakan Structural Equation Modelling (SEM) dengan alat statistik Smart Partial Least Square (SmartPLS). Structural Equation Modelling (SEM) merupakan pendekatan terintegrasi antara analisis faktor, model structural, dan analisis path. Metode yang digunakan untuk menganalisis uji kualitas data, uji hipotesis, dan uji analisis jalur adalah Partial Least Square (PLS). Partial least squares merupakan metoda analisis yang powerfull dan sering disebut juga sebagai soft modelling karena meniadakan asumsi - asumsi OLS (Ordinary Least Squares) regresi, seperti data harus terdistribusi normal secara multivariate dan tidak adanya problem multikolonieritas antar variabel eksogen Wold (1985) (dalam Ghozali 2015, 5). Analisis pada Smart Partial Least Square (SmartPLS) dapat dilakukan berdasarkan outer model dan inner model (Ghozali 2015, 7). Analisis outer model digunakan untuk mengetahui hubungan antara variabel laten dengan indikator-indikatornya. Analisis ini dapat dilakukan melalui convergent validity, discriminant validity, dan composite reliability. Analisis inner model / structural model adalah analisis yang digunakan untuk mengetahuihubungan antar variabel laten. Analisis inner model dapat dilakukan dengan analisis jalur dan $R$ square. 


\subsection{Uji Hipotesis}

Untuk pengujian hipotesis dengan menggunakan SmartPLS perlu dilakukan proses bootstrapping. Selanjutnya dilakukan analisis pada tabel path coefficients yang merupakan output setelah dilakukan proses bootstrapping. Pada tabel path coefficients yang perlu dilihat adalah nilai original sample $(O)$ yang menunjukkan terjadinya hubungan positif atau negatif antar konstruk, dan t-statistik yang mengindikasikan signifikansi hubungan antar konstruk. Pengaruh antar variabel dianggap signifikan pada tingkat 5\% jika nilai $t$-statistic lebih besar daripada t-tabel 1,96 (Ghozali 2015, 42). Kriteria pengujian dengan tingkat signifikansi (a) $=0.05$ ditentukan sebagai berikut :

a. Apabila $t$ hitung $>\mathrm{t}$ tabel maka $\mathrm{HO}$ ditolak dan Ha diterima

b. Apabila t hitung $<\mathrm{t}$ tabel maka $\mathrm{HO}$ diterima dan Ha ditolak

\subsection{Pengujian Analisis Jalur (Path Analysis)}

Pengujian analisis jalur bertujuan untuk mengetahui pengaruh langsung dan tidak langsung konstruk laten atau variabel penelitian. Hal ini dapat diketahui dengan melihat koefisien standardized yang dihasilkan dari perhitungan results for inner weights pada kolom original sample estimate. Bila nilai original sample estimate dari suatu pengaruh langsung lebih besar daripada perkalian original sample estimate pengaruh tidak langsung, maka suatu variabel tertentu tidak dapat memediasi suatu hubungan antar variabel. Namun bila nilai perkalian original sample estimate pada variabel dengan pengaruh tidak langsung lebih besar daripada nilai original sampel estimate variabel yang memiliki pengaruh langsung maka hal ini menunjukkan bahwa variabel tersebut dapat menjadi variabel mediasi.

\section{HASIL PENELITIAN DAN PEMBAHASAN}

\subsection{Tempat Dan Waktu Penelitian}

Penelitian ini dilakukan pada satuan kerja Inspektorat Kabupaten Banyuwangi berlokasi di Jl. KH Agus Salim 81 Banyuwangi. Pengumpulan data dilakukan melalui penyebaran kuesioner secara langsung kepada responden. Penyebaran kuesioner dimulai dari 11 April sampai 22 April 2016. Kuesioner diberikan dan diterima kembali oleh peneliti dengan waktu yang sudah ditentukan serta menyesuaikan dengan jadwal kerja Inspektorat Kabupaten Banyuwangi. Berdasarkan data yang berhasil dikumpulkan dalam penelitian ini, kuesioner yang dibagikan berjumlah 28 eksemplar berdasarkan jumlah auditor di Inspektorat Kabupaten Banyuwangi, dan 28 auditor bersedia menjawab atau mengisi kuesioner yang diberikan.

\subsection{Statistik Deskriptif}

Statistik deskriptif meliputi karakteristik responden dan deskriptif variabel penelitian. Hasil penelitian berdasarkan jenis kelamin auditor/pemeriksa Inspektorat Kabupaten Banyuwangi yang paling banyak berjenis kelamin laki - laki sebanyak 18 orang $(64,30 \%)$ dan berjenis kelamin perempuan sebanyak 10 orang $(35,70 \%)$. penelitian berdasarkan umur yang paling banyak berusia antara 30 hingga 50 tahun sebanyak 19 orang $(67,86 \%)$, dan berusia lebih dari 50 tahun sebanyak 6 orang $(21,43 \%)$ serta untuk usia kurang dari 30 tahun sebanyak 3 orang $(10,71 \%)$. Berdasarkan tingkat pendidikan yang paling banyak adalah tingkat strata 1 yaitu 21 orang $(78 \%)$, strata 2 yaitu 4 orang $(11,29 \%)$, dan tingkat SMU yaitu 3 orang $(10,71 \%)$. Berdasarkan pendidikan formal yang paling banyak adalah berpendidikan 
non akuntansi yaitu sebanyak 20 orang $(71,43 \%)$ sedangkan untuk yang berpendidikan akuntansi adalah 8 orang $(28,57 \%)$. Berdasarkan lama bekerja yang paling banyak adalah 12 sampai dengan 15 tahun sebanyak 14 orang (50\%), 8 sampai dengan 11 tahun sebanyak 8 orang $(28,57 \%), 1$ sampai dengan 3 tahun sebanyak 4 orang $(14,29 \%)$, dan 4 sampai dengan 7 tahun sebanyak 2 orang $(7,14 \%)$.

\subsection{Statistik Deskriptif Variabel Penelitian}

Variabel etika $\left(\mathrm{X}_{1}\right)$, pendidikan $(\mathrm{X} 2)$, pengalaman $(\mathrm{X} 4)$, profesionalisme $(\mathrm{Y})$, dan kualitas audit (Z) pada Inspektorat Kabupaten Banyuwangi dipersepsikan "baik" oleh sebagian besar pemeriksa (auditor) yang dibuktikan dengan diperolehnya nilai modus secara keseluruhan 4.

\subsection{Hasil Analisis Partial Least Square (PLS)}

\subsubsection{Menilai Outer Model atau Measurement Model}

Terdapat tiga kriteria di dalam penggunaan teknik analisa data dengan SmartPLS untuk menilai outer model yaitu convergent validity, discriminant validity, dan composite reliability.

\subsubsection{Convergent Validity}

Ukuran refleksif individual dikatakan tinggi jika berkorelasi lebih dari 0,70 dengan konstruk yang diukur. Namun menurut Chin 1998 (dalam Ghozali 2015) untuk penelitian tahap awal dari pengembangan skala pengukuran nilai loading 0,5 sampai 0,6 dianggap cukup memadai. Dalam penelitian ini akan digunakan batas loading factor sebesar 0,60. Hasil pengolahan dengan menggunakan SmartPLS nilai outer model atau korelasi antara konstruk dengan variabel pada masing-masing variabel terdapat satu indikator yang tidak memenuhi convergent validity yaitu Y6, karena indikator Y6 memiliki nilai loading factor kurang dari 0,60. Maka salah satu konstruk untuk variabel profesionalisme (Y) harus ada yang dieliminasi yaitu indikator Y6. Selanjutnya, dilakukan re-estimasi dan dari model yang baru tersebut diperoleh nilai loading factor di atas 0,60 untuk semua indikator dan dinyatakan valid atau telah memenuhi convergent validity.

\subsubsection{Discriminant validity}

Langkah ini dilakukan untuk memastikan bahwa setiap konsep dari masing variabel laten berbeda dengan variabel lainnya. Model mempunyai discriminant validity yang baik jika setiap nilai loading dari setiap indikator dari sebuah variabel laten memiliki nilai loading yang paling besar dengan nilai loading lain terhadap variabel laten lainnya. nilai loading factor untuk setiap indikator dari masing-masing variabel laten telah memiliki nilai loading factor yang paling besar dibanding nilai loading jika dihubungkan dengan variabel laten lainnya. Hal ini berarti bahwa setiap variabel laten telah memiliki discriminant validity yang baik dimana semua variabel laten memiliki pengukur yang berkorelasi lebih rendah dengan konstruk lainnya.

\subsubsection{Composite Reliability dan Average Variance Extracted (AVE).}

Kriteria validity dan reliabilitas juga dapat dilihat dari nilai reliabilitas suatu konstruk dan nilai Average Variance Extracted (AVE) dari masing-masing konstruk. Konstruk dikatakan memiliki reliabilitas yang tinggi jika nilainya 0,70 dan AVE berada diatas 0,50 . 
Tabel 2 Nilai Composite Reliability dan Average Variance Extracted (AVE)

\begin{tabular}{lccc}
\hline \multicolumn{1}{c}{ Variabel } & $\begin{array}{c}\text { Composite } \\
\text { Reliability }\end{array}$ & $\begin{array}{c}\text { Average } \\
\text { Variance } \\
\text { Extracted (AVE) }\end{array}$ & $\begin{array}{l}\text { Akar Kuadrat } \\
\text { AVE }\end{array}$ \\
\hline X1 (Etika) & 0,905 & 0,658 & 0,811 \\
X2 (Pendidikan) & 0,926 & 0,759 & 0,871 \\
X3 (Pengalaman) & 0,952 & 0,772 & 0,878 \\
Y(Profesionalisme) & 0,908 & 0,590 & 0,768 \\
Z (Kualitas Audit) & 0,925 & 0,611 & 0,781 \\
\hline
\end{tabular}

Sumber: Hasil Pengolahan Data

\subsubsection{Pengujian Model Struktural (Inner Model)}

Langkah ini dilakukan untuk melihat hubungan antara konstruk, nilai signifikansi dan $R$-square dari model penelitian. Model struktural dievaluasi dengan menggunakan $R$-square untuk konstruk dependen uji t serta signifikansi dari koefisien parameter jalur struktural.

Tabel 3 Nilai $R$-Square

\begin{tabular}{cc}
\hline Variabel & R-Square \\
\hline Y (Profesionalisme) & 0,424 \\
Z (Kualitas Audit) & 0,850 \\
\hline
\end{tabular}

Sumber: Hasil Pengolahan Data

\subsection{Pengujian Hipotesis}

Tabel 4 Nilai Result for Inner Weight

\begin{tabular}{lcccc}
\hline Variabel & $\begin{array}{c}\text { Original } \\
\text { Sample } \\
\text { Estimate }\end{array}$ & $\begin{array}{c}\text { Mean of } \\
\text { Sub- } \\
\text { samples }\end{array}$ & $\begin{array}{c}\text { Standard } \\
\text { Deviation }\end{array}$ & T-Statistic \\
\hline X1 -> Y & 0,296 & 0,313 & 0,130 & 2,273 \\
X1 -> Z & 0,278 & 0,268 & 0,101 & 2,755 \\
X2 -> Y & 0,235 & 0,173 & 0,159 & 1,483 \\
X2 -> Z & 0,008 & 0,027 & 0,095 & 0,088 \\
X3 -> Y & 0,199 & 0,258 & 0,146 & 1,360 \\
X3 -> Z & 0,600 & 0,573 & 0,085 & 7,088 \\
Y -> Z & 0,168 & 0,186 & 0,067 & 2,513 \\
\hline
\end{tabular}

Sumber: Hasil Pengolahan Data

\subsection{Perhitungan Analisis Jalur (Path Analysis)}

Bagian ini menjelaskan perhitungan pengaruh variabel etika, pendidikan, dan pengalaman sebagai variabel bebas (X) berpengaruh langsung dan tidak langsung terhadap kualitas audit (Z), melalui variabel intervening profesionalisme (Y). Berikut penghitungan hipotesis koefisien jalurnya: 


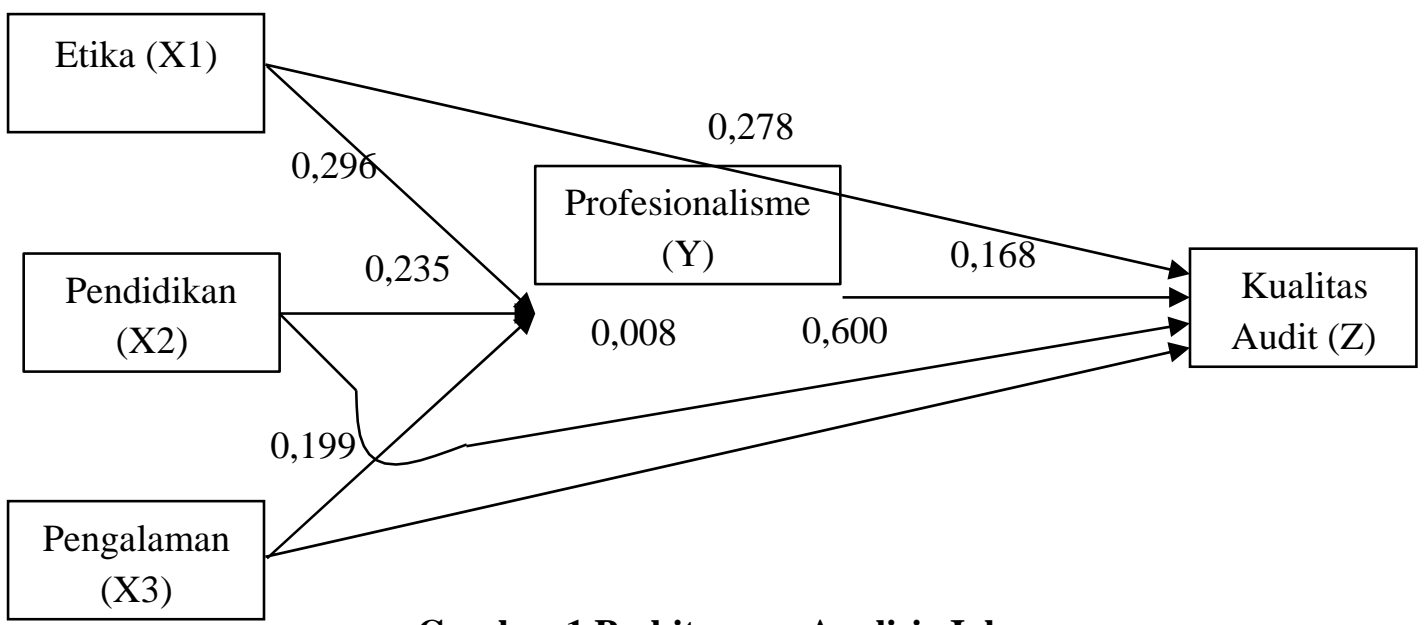

Gambar 1 Perhitungan Analisis Jalur

Untuk pengaruh tidak langsung dari setiap variabel bebas $(\mathrm{X})$ terhadap variabel terikat $(\mathrm{Z})$ melalui variabel intervening $(\mathrm{Y})$ dapat dihitung sebagai berikut:

1. Pengaruh etika terhadap kualitas audit melalui profesionalisme $=0,296 \mathrm{x}$ $0,168=0,050$

2. Pengaruh pendidikan terhadap kualitas audit melalui profesionalisme $=0,235$ $\mathrm{x} 0,168=0,039$

3. Pengaruh pengalaman terhadap kualitas audit melalui profesionalisme $=$ $0,199 \times 0,168=0,033$

4. $\mathrm{e} 1=(1-0,424)_{2}=0,331 \mathrm{e} 2$

\subsection{Pembahasan}

\subsubsection{Pengaruh Etika Terhadap Profesionalisme}

Etika berpengaruh terhadap profesionalisme. Hal ini menunjukkan bahwa hipotesis pertama yang menyatakan bahwa etika berpengaruh terhadap profesionalisme adalah diterima. Temuan ini mengandung makna bahwa semakin baik etika yang dimiliki pemeriksa yang bekerja di Inspektorat Kabupaten Banyuwangi akan mampu meningkatkan profesionalisme. Kesimpulan ini menunjukkan bahwa faktor etika yang diukur melalui integritas, objektivitas, kerahasiaan, dan kompetensi merupakan suatu faktor yang menentukan profesionalisme pada Inspektorat Kabupaten Banyuwangi. Temuan empiris yang diperoleh adalah mendukung temuan Putri dan Januarti (2011) pada Internal Auditor BPKP Semarang, yang menyatakan bahwa aturan etika mempunyai pengaruh positif terhadap terbentuknya profesionalisme internal auditor. Dan penelitian Cahayu (2013) yang dilakukan pada Inspektorat Jenderal Kementerian Perdagangan Republik Indonesia menjelaskan bahwa etika berpengaruh signifikan terhadap profesionalisme auditor internal.

\subsubsection{Pengaruh Pendidikan Terhadap Profesionalisme}

Pendidikan tidak berpengaruh terhadap profesionalisme. Hasil penelitian ini menunjukkan bahwa hipotesis kedua yang menyatakan bahwa pendidikan berpengaruh terhadap profesionalisme ditolak. Hal ini menunjukkan bahwa pendidikan yang diukur dengan indikator tingkat pendidikan, pendidikan, dan pelatihan berkelanjutan, pengembangan teknik, dan metode audit serta evaluasi pendidikan dan pelatihan tidak berpengaruh terhadap profesionalisme. Hal ini disebabkan karena latar 
belakang pendidikan formal auditor pada Inspektorat Kabupaten Banyuwangi yang paling banyak adalah dari non akuntansi, hal ini dapat dilihat dari statistik deskriptif demografi responden bahwa jumlah auditor yang berpendidikan akuntansi sebanyak 8 orang $(28,57 \%)$ lebih sedikit dibanding jumlah auditor yang berpendidikan non akuntansi yang berjumlah 20 orang $(71,43 \%)$, hal ini akan berpengaruh terhadap luas cakupan ilmu pengetahuan yang dimiliki oleh auditor. Dalam Peraturan Menteri Negara Pendayagunaan Aparatur Negara Nomor PER/05/M.PAN/03/2008 tentang Standar Audit APIP dijelaskan bahwa kompetensi teknis yang harus dimiliki oleh auditor adalah auditing, akuntansi, administrasi pemerintahan, dan komunikasi. Di samping wajib memiliki keahlian tentang Standar Audit, kebijakan, prosedur, dan praktik-praktik audit, auditor harus memiliki keahlian yang memadai tentang lingkungan pemerintahan sesuai dengan tugas pokok dan fungsi unit yang dilayani oleh APIP. Dalam hal auditor melakukan audit terhadap sistem keuangan, catatan akuntansi dan laporan keuangan, maka auditor wajib mempunyai keahlian atau mendapatkan pelatihan di bidang akuntansi sektor publik dan ilmu-ilmu lainnya yang terkait dengan akuntabilitas audit. APIP pada dasarnya berfungsi melakukan audit di bidang pemerintahan, sehingga auditor harus memiliki pengetahuan yang berkaitan dengan administrasi pemerintahan. Pencapaian keahlian tersebut dimulai dengan pendidikan formal auditor diperluas dengan pengalaman selanjutnya dalam praktik audit untuk memenuhi persyaratan sebagai seorang profesional, auditor harus melalui pelatihan teknis maupun pendidikan yang cukup. Temuan empiris yang diperoleh adalah tidak mendukung temuan Widiyanto dan Indrawati (2005), Prayanti dan Sujana (2012) dan Wardayati (2006). Perbedaan hasil ini juga disebabkan adanya perbedaan objek penelitian Temuan empiris yang diperoleh adalah mendukung temuan Cahayu (2013) bahwa pendidikan tidak berpengaruh signifikan terhadap profesionalisme auditor internal Inspektorat Jenderal Kementerian Perdagangan Republik Indonesia.

\subsubsection{Pengalaman Tidak Berpengaruh Terhadap Profesionalisme}

Hasil penelitian ini menunjukkan bahwa hipotesis ketiga yang menyatakan bahwa pengalaman berpengaruh terhadap profesionalisme adalah ditolak. Hal ini disebabkan karena pengalaman tidak mempunyai peranan dalam meningkatkan profesionalisme auditor pada Inspektorat Kabupaten Banyuwangi. Data statistik deskriptif berdasarkan lama bekerja auditor Kabupaten Banyuwangi menunjukkan lebih banyak yang bekerja antara 12 sampai dengan 15 tahun sebanyak 14 orang (50\%), 8 sampai dengan 11 tahun sebanyak 8 orang (28,57\%), 1 sampai dengan 3 tahun sebanyak 4 orang $(14,29 \%)$, dan 4 sampai dengan 7 tahun sebanyak 2 orang $(7,14 \%)$ tetapi hal ini tidak berpengaruh terhadap profesionalisme auditor Kabupaten Banyuwangi. Auditor pada Inspektorat Kabupaten Banyuwangi dalam melaksanakan tugasnya berdasarkan Kode Etik Dan Standar Audit APIP yang diatur dalam Peraturan Menteri Pendayagunaan Aparatur Negara No. PER/04/M.PAN/03/2008 tanggal 31 Maret 2008 sehingga dalam hal ini pengalaman atau lama bekerjanya auditor tidak berpengaruh terhadap profesionalisme auditor. Selain itu tugas auditor di Inspektorat Kabupaten Banyuwangi merupakan rutinitas yang diulang untuk setiap periode kerja auditor yaitu memeriksa seluruh SKPD yang ada di lingkup wilayah kerja Inspektorat Kabupaten Banyuwangi sehingga pengalaman tidak memiliki pengaruh yang signifikan terhadap profesionalisme yang di mana keputusan masih berada pada manajer puncak atau pimpinan, hal ini berbeda dengan auditor pada perusahaan profit oriented, di mana auditor akan mengaudit berbagai perusahaan yang berbeda dan 
memiliki pengalaman serta pengetahuan yang semakin luas, sehingga auditor pada perusahaan profit oriented pengalaman akan berpengaruh signifikan terhadap profesionalisme, seperti penelitian yang dilakukan Wardayati (2006). Temuan empiris yang diperoleh adalah tidak mendukung temuan Sumardi (2001), Widiyanto dan Indrawati (2005) dan Wardayati (2006). Temuan empiris yang diperoleh adalah mendukung temuan Cahayu (2013).

\subsubsection{Etika Berpengaruh Secara Positif Terhadap Kualitas Audit}

Hal ini menunjukkan bahwa hipotesis keempat yang menyatakan bahwa etika berpengaruh terhadap kualitas audit diterima. Kesimpulan ini menunjukkan bahwa semakin baik etika yang dimiliki pemeriksa yang bekerja di Inspektorat Kabupaten Banyuwangi akan mampu meningkatkan kualitas audit. Hal ini berarti faktor etika yang diukur melalui integritas, objektivitas, kerahasiaan, dan kompetensi merupakan suatu faktor yang menentukan kualitas audit pada Inspektorat Kabupaten Banyuwangi. Temuan empiris yang diperoleh adalah mendukung temuan Kovinna dan Betri (2014), Kisnawati (2012).

\subsubsection{Pendidikan Tidak Berpengaruh Terhadap Kualitas Audit}

Hasil penelitian ini menunjukkan bahwa hipotesis kelima yang menyatakan bahwa pendidikan berpengaruh terhadap kualitas audit adalah ditolak. Tidak berpengaruhnya pendidikan terhadap kualitas audit disebabkan karena jika dilihat dari hasil kuesioner rata-rata responden sudah paham dengan pentingnya sifat skeptis pada variabel kualitas audit (z) pada indikator sikap skeptis, tetapi untuk yang masih kurang paham atau jawaban tidak setuju dengan nilai (2) masih mendominasi sebesar 17,86\% dibanding dengan yang memilih menjawab netral dengan poin (3) sebesar 14,29 \%. Hal ini mengindikasikan bahwa masih kurangnya kesadaran akan pentingnya sifat skeptis yang harus dimiliki oleh auditor Inspektorat Kabupaten Banyuwangi terhadap audit yaitu Satuan Kerja Perangkat Daerah yang ada di Banyuwangi. Dalam hal rekomendasi yang dibuat oleh auditor Inspektorat Kabupaten Banyuwangi terhadap SKPD yang telah diaudit masih tergantung pimpinan sehingga hal ini berkaitan dengan tindak lanjut rekomendasi oleh auditor untuk SKPD yang ada di Banyuwangi. Hal ini menjadi kendala yang masih dihadapi auditor dalam upaya meningkatkan kualitas audit di seluruh SKPD yang ada di Banyuwangi. Temuan empiris yang diperoleh adalah mendukung temuan Subhan (2012). Kesimpulan ini menunjukkan bahwa faktor pendidikan yang diukur melalui tingkat pendidikan, pendidikan, dan pelatihan berkelanjutan, pengembangan teknik, dan metode audit, serta evaluasi pendidikan dan pelatihan bukan merupakan suatu faktor yang menentukan kualitas audit pada Inspektorat Kabupaten Banyuwangi.

\subsubsection{Pengalaman Berpengaruh Terhadap Kualitas Audit}

Hal ini menunjukkan bahwa hipotesis keenam yang menyatakan bahwa pengalaman berpengaruh terhadap kualitas audit diterima. Semakin baik pengalaman yang dimiliki pemeriksa yang bekerja di Inspektorat Kabupaten Banyuwangi akan mampu meningkatkan kualitas audit. Kesimpulan ini mengindikasikan bahwa faktor pengalaman yang diukur melalui lamanya bekerja dan banyaknya penugasan merupakan suatu faktor yang menentukan kualitas audit pada Inspektorat Kabupaten Banyuwangi. Temuan empiris yang diperoleh adalah mendukung temuan Sembiring dan Rusdiana (2014), Sylvie Bolang et al. (2013) dan Wardayati et. Al (2015). 


\subsubsection{Profesionalisme Berpengaruh Positif Terhadap Kualitas Audit}

Hal ini menunjukkan bahwa hipotesis ketujuh yang menyatakan bahwa profesionalisme berpengaruh terhadap kualitas audit diterima. Kesimpulan ini mengindikasikan bahwa semakin baik profesionalisme yang dimiliki pemeriksa yang bekerja di Inspektorat Kabupaten Banyuwangi akan mampu meningkatkan kualitas audit. Temuan empiris yang diperoleh mendukung temuan Susilawati dan Atmawinata (2014), Wardayati (2006) dan Rosnidah (2011).

\section{KESIMPULAN, IMPLIKASI, KETERBATASAN, DAN SARAN PENELITIAN 6.1 Kesimpulan}

Penelitian ini merupakan lanjutan penelitian-penelitian sebelumnya yang menyoroti pengaruh etika, pendidikan, pengalaman, dan profesionalisme auditor terhadap kualitas audit di Inspektorat. Berdasarkan hasil analisis data dalam penelitian ini, pengujian model baik langsung maupun tidak langsung secara keseluruhan menunjukkan kesesuaian yang cukup baik (poor-fit) untuk menghasilkan konfirmasi atas hubungan kausalitas antar variabel. Dari tujuh hipotesis yang diajukan hanya variabel etika terhadap profesionalisme yang diterima, dan untuk pengaruh variabel pendidikan dan pengalaman terhadap profesionalisme ditolak. untuk etika, pengalaman, dan profesionalisme terhadap kualitas audit diterima dan untuk variabel pengaruh pendidikan terhadap kualitas audit ditolak. metode pengujian hipotesis dalam penelitian ini menggunakan metode Structural Equation Modelling (SEM) dengan alat statistik Smart Partial Least Square (SmartPLS). Structural Equation Modelling (SEM) merupakan pendekatan terintegrasi antara analisis faktor, model structural dan analisis path.

\subsection{Implikasi Penelitian}

Bagi Ilmu Pengetahuan. Penelitian ini memberikan bukti bahwa terdapat pengaruh positif antara etika terhadap profesionalisme auditor Inspektorat Kabupaten Banyuwangi dan terdapat pengaruh positif antara etika, pengalaman dan profesionalisme terhadap kualitas audit. Penelitian ini membuka peluang lebih lanjut bagi peneliti selanjutnya untuk mengadakan penelitian tentang profesionalisme dan kualitas audit pada instansi sektor publik

Bagi Inspektorat Kabupaten Banyuwangi. Untuk menghasilkan kualitas hasil pemeriksaan yang baik dan untuk memelihara profesionalisme dan kualitas audit Inspektorat Kabupaten Banyuwangi maka pendidikan dan pelatihan berkelanjutan serta pengalaman lebih ditingkatkan mengingat perkembangan standar, metode, prosedur dan teknik pemeriksaan terutama pada auditor internal. Meningkatkan kesadaran akan pentingnya sifat skeptis yang harus dimiliki oleh auditor Inspektorat Kabupaten Banyuwangi sehingga kualitas audit makin mampu ditingkatkan. Auditor dengan latar belakang pendidikan akuntansi memiliki pengaruh terhadap luas cakupan ilmu pengetahuan yang dimiliki auditor, sehingga berpengaruh terhadap profesionalisme auditor internal dalam melaksanakan tugas. Sebaiknya dalam penerimaan karyawan Inspektorat Kabupaten Banyuwangi dari latar belakang pendidikan formal jurusan akuntansi lebih diutamakan. 


\subsection{Keterbatasan Penelitian}

1. Dalam melakukan penelitian, peneliti tidak melakukan wawancara secara langsung terhadap seluruh responden, peneliti hanya melakukan wawancara pada sebagian responden karena metode yang diterapkan adalah metode sensus dengan menyebar kuesioner kepada para responden. Sehingga peneliti tidak dapat mengetahui secara langsung situasi dan kondisi responden saat mengisi kuesioner, serta tidak terlibat secara langsung dengan aktivitas yang ada dalam instansi tersebut.

2. Penelitian ini hanya melibatkan satu institusi saja, yaitu Inspektorat Kabupaten Banyuwangi dan kesimpulan yang diambil mungkin hanya berlaku pada Inspektorat Kabupaten Banyuwangi dan tidak dapat digeneralisasikan ke Inspektorat se-Indonesia

3. Sampel yang digunakan dalam penelitian ini masih sangat terbatas dan hanya berdasarkan pemeriksa yang bekerja di Inspektorat Kabupaten Banyuwangi yang telah bersertifikasi sehingga kurang memperhatikan aspek latar belakang pendidikan formal yang dimiliki.

4. Variabel yang digunakan untuk mengukur pengaruhnya terhadap kualitas auditor pada penelitian ini hanya sebatas etika, pendidikan, pengalaman dan profesionalisme. Sebagaimana yang terdapat di dalam Peraturan Menteri Negara Pendayagunaan Aparatur Negara No. Per/05/M.Pan/03/2008 tentang Standar Audit Aparat Pengawasan Intern Pemerintah (APIP) bahwa masih banyak faktor lain yang dapat mempengaruhi kualitas auditor.

\subsection{Saran}

1. Penelitian mendatang sebaiknya melakukan sebuah penelitian dengan menggunakan metode wawancara langsung untuk mengumpulkan data penelitian agar dapat mengurangi adanya kelemahan terkait internal validity.

2. Peneliti juga menyarankan untuk penelitian selanjutnya agar memperluas objek penelitian pada beberapa aparat inspektorat kabupaten/kota di Provinsi Jawa Timur, sehingga hasilnya dapat digeneralisasi.

3. Menambah jumlah sampel yang diteliti dan dalam pemilihan sampel sebaiknya staf inspektorat yang memiliki latar belakang pendidikan formal minimal strata satu atau yang setara dan yang memiliki latar belakang pendidikan akuntansi.

4. Dalam penelitian selanjutnya diharapkan dapat menggunakan variabel lain seperti tingkat kualifikasi profesi, continuing professional development, supervisi, komunikasi, dan lainnya sehingga diperoleh temuan yang lebih baik dalam menjelaskan tentang profesionalisme dan kualitas audit.

\section{DAFTAR PUSTAKA}

Arens, Alvin A., Randal J.E dan Mark S.B. 2010. Auditing dan Pelayanan Verifikasi, Pendekatan Terpadu.Jilid 1, Edisi Kesembilan. Penerbit PT.Indeks. Jakarta.

Ashari, Ruslan. 2011. Pengaruh Keahlian, Independensi, dan Etika terhadap Kualitas Auditor pada Inspektorat Provinsi Maluku Utara. Skripsi. Universitas Hasanuddin Makassar.

Bastian, Indra. 2007. Audit Sektor Publik. Jakarta : Salemba Empat. 
Beer, M. and Spector, B. 1985. Corporate Wide Transformation in HRM. In Walton R. E. and Lawrence P. R. HRM: Trends and Challenges. Boston, MA: Harvard University Business School Press. No. 219-253.

Budi, Sasongko. Basuki dan Hendaryatno. 2004. Jurnal. Internal Auditor dan Dilema Etika. SNA VII.

Cahayu, Dwi R. 2013. Pengaruh Etika, Pendidikan, Dan PengalamanTerhadap Profesionalisme Auditor Internal Dengan Motivasi Sebagai Variabel Intervening". Studi kasus pada Inspektorat Jenderal Kementerian Perdagangan Republik Indonesia, Skripsi Universitas Islam Negeri Syarif Hidayatullah, Jakarta.

Ghozali, Imam dan Latan Hengky. 2015. Partial Least Squares Konsep, Teknik Dan Aplikasi Menggunakan Program SmartPLS 3.0 Untuk Penelitian Empiris. Badan Penerbitan Universitas Diponegoro, Semarang

Indriantoro, Nur dan Supomo. 2009. Metodologi Penelitian Bisnis untuk Akuntansi dan Manajemen. Edisi Pertama. Cetakan Kedua. BPFE. Yogjakarta

Jensen, M. C and Meckling, W.H. 1976. Theory of the Firm : Managerial Behavior, Agency Costs and Ownership Structure. Journal of Financial Economics,Oktober, 1976, V. 3, No. 4, pp. 305-360 Avalaible from:http://papers.ssrn.com

Kamidin, M (2010), "Pengaruh kompetensi terhadap prestasi kerja pegawai sekretariat daerah Kabupaten Bantaeng," Jurnal Economic Resources, Vol. 11, No. 30, pp. 79-91.

Kisnawati, Baiq. 2012. Pengaruh Kompetensi, Independensi dan Etika Profesi Terhadap Kualitas Audit (Studi Empiris Pada Inspektorat Kabupaten dan Kota Se-Pulau Lombok), Jurnal Bisnis dan Kewirausahaan, Vol.8, No.3, Hal. 158169.

Kovinna, Fransiska Dan Betri. 2014. Pengaruh Independensi, Pengalaman Kerja, Kompetensi, Dan Etika Auditor Terhadap Kualiatas Audit. STIE MDP.

Mardiasmo, 2007, Akuntansi Sektor Publik, Edisi ketiga, Yogyakarta: Andi Ofset. Pebryanto, Setyadi. 2013. Pengaruh Tingkat Pendidikan Formal, Pengalaman Kerja, Tingkat Kualifikasi Profesi, Continuing Professional Development Terhadap Kualitas Audit di Badan Pemeriksa Keuangan (BPK) RI Perwakilan Sulawesi Selatan. Skripsi. Fakultas Ekonom dan Bisnis Universitas Hasanuddin Makasar.

Peraturan Menteri Dalam Negeri Nomor 59 Tahun 2007 Tentang Pedoman Pengelolaan Keuangan Daerah.

PP No.64 Tahun 2007 Tentang Pedoman Teknis Organisasi Tata Kerja Inspektorat Provinsi dan Kabupaten/Kota.

Peraturan Menteri Negara Pendayagunaan Aparatur Negara Nomor: PER/04/M.PAN/03/2008. Kode Etik Aparat Pengawasan Intern Pemerintah.

Peraturan Menteri Negara Pendayagunaan Aparatur Negara nomor PER/05/M.PAN/03/2008. Standar Audit Aparat Pengawasan Intern Pemerintah. Jakarta.

Pusat Pendidikan dan Pelatihan Pengawasan BPKP ,2008, Kode Etik dan Standar Audit.

Peraturan Kepala Badan Pengawasan Keuangan Dan Pembangunan Nomor : PER 211/K/JF/2010 
Prayanti, Ni Nyoman Ristya dan I Ketut Sujana. Agustus 2012. Pengaruh Supervisi, Profesionalisme, Tingkat Pendidikan, dan Komunikasi dalam Tim Pada Kinerja Auditor Perwakilan Badan Pengawasan Keuangan dan Pembangunan (BPKP) Provinsi Bali. Jurnal Riset Akuntansi, Vol. 2, No. 2, Hal. 156-165.

Putri, Harlynda Anindhya dan Januarti, Indira. 2011. Pengaruh Aturan Etika Dan Independensi Terhadap Kepuasan Kerja Internal Auditor Dengan Profesionalisme Sebagai Variabel Intervening. Universitas Diponegoro.

Rosina, Dwi R, 2012, Pengaruh Profesionalisme terhadap Temuan Audit pada Satuan Pengawasan Intern PT. INTI (Persero). Skripsi UniversitasPendidikan Indonesia.

Rosnidah, Ida, Juli 2011. Analisis Dampak Motivasi dan Profesionalisme terhadap Kualitas Audit Aparat Inspektorat dalam Pengawasan Keuangan Daerah. Pekbis Jurnal, Vol.3, No.2, Hal. 456-466.

Sylvie Bolang, Marrieta, Sondakh, Jullie J.h \& Morasa, Jenny . 2013. Pengaruh Kompetensi, Independensi dan Pengalaman Terhadap Kualitas Audit Aparat Inspektorat Kota Tomohon Dalam Pengawasan Pengelolaan Keuangan Daerah, Jurnal Riset Akuntansi Dan Auditing Magister Akuntansi, Fakultas Ekonomi UNSRAT Vol.4, N0.2.

Sembiring, Andi Yahya Dan Rustiana. 2014. Pengaruh Pengalaman Dan Akuntabilitas Terhadap Kualitas Audit Internal Inspektorat Daerah Istimewa Yogyakarta. Universitas Atmajaya Yogyakarta.

Subhan, 2012, Pengaruh Latar Belakang Pendidikan, Kompetensi Tehnis, Pendidikan Dan Pelatihan Berkelanjutan Dan Pengalaman Kerja Terhadap Kualitas Hasil Pemeriksaan ( Studi Pada Inspektorat Kabupaten Pemekasan), Universitas Madura

Sugiyono, 2009. Statistika untuk penelitian (edisi pertama). Bandung: Alfabeta. Sumardi, 2001. Pengaruh Pengalaman Terhadap Profesionalisme Serta Pengaruh Profesionalisme Terhadap Kinerja Dan Kepuasan Kerja. Tesis : Universitas Diponegoro Semarang.

Susilawati Dan Atmawinata, Maya R. Oktober 2014. Pengaruh Profesionalisme dan Independensi Auditor Internal Terhadap Kualitas Audit: Studi Pada Inspektorat Propinsi Jawa Barat. Jurnal Etikonomi Vol. 13 No. 2.

Standar Pemeriksa Keuangan Negara (SPKN). 2007. Standar Pemeriksa Keuangan Negara. Diakses melalui http://www.bpk.go.id . [15/12/2015].

Wardayati, Siti Maria. 2006. Pengaruh individual rank, pengalaman kerja, dan firm size terhadap profesionalisme dan hasil kerja auditor intern. Disertasi. Universitas Padjajaran Bandung.

Wardayati, Siti Maria, Anisa dan Khoirul. 2015. The Effect of Accountability, Objectivity, Integrity, Working Experience, Competence, Independence and Motivation of the Examiner toward the Quality of Inspection Result at the Inspectorate of Lumajang Regency. Proceedings, 2nd Global Conference on Business and Social Science. September 17-18, Bali, Indonesia.

Wibowo.2008. Manajemen Kinerja. Jakarta : PT. Raja Grafindo Persada. Jakarta Widiyanto, Adi Kurniawan Dwi dan Indrawati Yuhertian. 2005. Pengaruh

Pendidikan, Pengalaman dan Pelatihan terhadap Profesionalisme Auditor Pemerintah yang Bekerja Pada Badan Pengawas Kota Surabaya. Konferensi Nasional Akuntansi, Jakarta. 